\title{
NotA INTRODUTÓRIA - ESTUdOS CULTURAIS, Cidadania e Democracia
}

\author{
Moisés de Lemos Martins, Urbano Sidoncha \& Messias Bandeira
}

Os modelos de pertença social mudaram radicalmente nas últimas décadas, pelo impacto que a mobilização tecnológica da época tem na vida dos indivíduos e das sociedades. As tecnologias da informação, com consequências imparáveis nos fluxos globais, na interpenetração de culturas, na reivindicação de novos direitos identitários, religiosos, étnicos e de género, vieram subverter, com efeito, as lealdades tradicionais à nação, à religião, à classe, assim como às identidades de género. Entretanto, a multiplicação da informação e, a acompanhá-la, a obsidiante influência dos média na sociedade, fizeram com que as redes sociotécnicas tenham vindo ocupar um lugar de importância inalienável na afirmação de novos movimentos sociais, com impactos decisivos na cultura e nas artes.

Nestas circunstâncias, podemos dizer que as transformações de natureza tecnológica conduziram a profundas alterações das estruturas sociais, e também da organização das comunidades humanas. E é essa a razão pela qual a noção de cidadania foi sendo aprofundada, e mesmo reformulada, abrindo-se ao reconhecimento, político, social e económico, de novas formas de pertença, e dando resposta à reivindicação de novos direitos sociais, particularmente baseados na diversidade e na diferença, sexual, racial, étnica, diaspórica, ecológica, tecnológica e cosmopolita.

Este volume tem como objetivo refletir sobre o modo como os indivíduos são constituídos e emergem nos média como sujeitos falantes e atores sociais, sendo dada particular atenção às assimetrias e às desigualdades na repartição da palavra. Os movimentos sociais e políticos, o ativismo digital, a mobilização dos média e das redes culturais na luta por direitos, sociais, culturais, políticos e económicos, bem como o poder que podem exercer na sociedade, contribuindo para a sua mudança social e política, são alguns dos temas tratados e aprofundados.

A ideia de poder perpassa este número dedicado à democracia e à cidadania. Como sustenta Foucault (1975/2010, p. 12), a "verdade não existe fora do poder ou sem poder", porque nunca agimos como queremos, mas sim como podemos, em condições concretas de espaço, tempo e interlocução. E, além disso, as sociedades constroem regimes de verdade, mobilizando discursos que fazem funcionar como verdadeiros (Martins, 2017). Com efeito, o jogo dialógico do discurso "repete ordens, quando faz supor que apenas afirma a liberdade" (Martins, 2017, p. 11).

O ponto de vista específico que os Estudos Culturais desenvolvem sobre os fenómenos de poder, que tanto assumem, como contestam, é o de problematizarem a divisão entre o hegemónico e o contra-hegemónico, que o mesmo é dizer, o de interrogarem a fronteira entre as margens e o centro, bem como as divisões estruturais, ou então, os ténues limites entre cultura, sociedade e economia (Durin, 1992/2007). 
A introdução ao debate sobre as relações entre cultura e poder, que este número da Revista Lusófona de Estudos Culturais / Lusophone Journal of Cultural Studies tematiza, é feita por Paulo Serra e Bruno Serra. Alinhando pelo entendimento que os Estudos Culturais fazem da diversidade cultural e dos média, enquanto elementos centrais das sociedades contemporâneas, estes autores interrogam as atuais condições de realização da democracia e da cidadania. Para Paulo Serra e Bruno Serra, o investigador que trabalha em Estudos Culturais adotará, sempre, uma postura crítica e política. Explorando o conceito de democracia plural, pela convocação de Laclau e Mouffe (1985/2001), para os quais "uma política democrática e radical" procura respeitar as diferenças e a diversidade cultural, os autores enaltecem a organização democrática, que seja capaz de respeitar a pluralidade e a diferença das culturas, não apenas a nível nacional, mas também a nível global.

Os trabalhos de Albino Rubim e Sérgio Silveira analisam o complexo panorama político, sociocultural e económico do Brasil contemporâneo. O alargado debate sobre a natureza da democracia, com infindáveis lutas pela definição e delimitação da ordem democrática, tem ganho grande centralidade na cena nacional e internacional. $\mathrm{E}$ no entender de Albino Rubim, acontece um debate similar com a cultura, muito embora menos intenso, dado que o campo social em questão tem menor centralidade. $O$ autor assinala a ausência de políticas de comunicação e de cultura no Brasil, que combatam a ausência de pluralismo dos média brasileiros, assim como a sua partidarização exacerbada. De modo muito particular, considera que a falta de democraticidade da imprensa e da comunicação tem constituído um sério obstáculo no processo de democratização da sociedade brasileira. O trabalho de Sérgio Silveira, por sua vez, analisa a conjuntura política brasileira e o "golpe de Estado", que destituiu a presidente eleita Dilma Rousseff. Este entendimento estriba-se, também, no papel antidemocrático que os média jogaram neste processo. Articulando as noções foucaultianas de regime de verdade e de prática discursiva, com a noção do que designa como "política de escândalo", o autor descreve a formação de um bloco social e político hegemónico, constituído pelos média, pelo Ministério Público e pelo Poder Judiciário. E classifica como prática de cinismo institucional a política de Estado assente na ideia do combate à corrupção.

Paula Espírito Santo e Bruno Ferreira Costa analisam os perfis da filiação partidária numa perspetiva comparada dos três principais partidos portugueses, com assento parlamentar. Os autores procuram identificar as razões para a diminuição e a falta de interesse pela participação partidária, mas também pela política em geral. É objetivo deste estudo perceber de que modo os diversos agentes de socialização política, e em especial a família, promovem a participação partidária. Tendo aplicado um inquérito online ao universo de filiados do PS e CDS/PP, assim como aos delegados do PSD, entre finais de dezembro de 2012 e finais de setembro de 2014, os autores procuram explorar a relação do percurso educativo, profissional e social dos cidadãos com a participação partidária. Embora os autores considerem que os novos movimentos sociais têm a potencialidade de criar alternativas à participação e ao envolvimento cívico dos cidadãos, a tendência nos resultados é para uma autodefinição dos inquiridos como razoavelmente ativos na atividade partidária. 
A análise das profissões que acedem ao campo político é realizada no artigo seguinte, da autoria de Esser Silva e Moisés de Lemos Martins. Trata-se de um trabalho que mobiliza os estudos de Foucault sobre parresía e elutéria, assim como a noção weberiana de fechamento partidário, examinando o modo como os profissionais da política articulam a sua existência entre a vida civil e a vida estatal. Abordando o caso dos deputados da Assembleia da República Portuguesa, os autores constatam que na Assembleia predominam "economistas", "advogados" e "professores", enquanto membros ativos da classe eleita. A questão do poder é de novo abordada neste texto. Como referem Esser Silva e Moisés de Lemos Martins, a ação dos membros do partido político moderno parece orientar-se, sobretudo, para a conquista patrimonial, em que "dois poderes especificamente políticos (...), o poder militar e o judicial", são exercidos "sobre aqueles que Ihe estão patrimonialmente submetidos" (Weber, 2004, p. 240).

Entretanto, José Eduardo Franco reflete sobre o modo como determinados axiomas teológicos bíblicos forneceram fundamentos para o ideário universalista do cristianismo, enquanto primeira tradição religiosa com um horizonte expansionista à escala global. O autor problematiza o fenómeno da protoglobalização como tendo, na sua raiz, um móbil religioso, considerando que foi neste meio que surgiram os primeiros instrumentos e soluções globais para atender aos desafios trazidos pelo processo de conhecimento do mundo.

Recusar a sobredeterminação da política, da cultura, da educação, da informação e da comunicação pela economia e pela finança, e fomentar, ao mesmo tempo, uma nova consciência crítica, é a proposta de Fernando Pereira Marques, de confronto com a realidade atual. Para o autor, a espetacularização do poder e do Estado, por via dos aparelhos mediáticos, contribui para ocultar a desumanização tecnológico mercantil, que marca a sociedade na sua globalidade e, em particular, como já foi referido anteriormente (ver os trabalhos de Albino Rubim, Sérgio Silveira ou Esser Silva e Moisés de Lemos Martins), o ensino e a cultura.

O sentido comum é o mote de reflexão de José Gomes Pinto, que utiliza esta noção como mecanismo de resolução de problemas, embora também chame à atenção para o facto de ela poder constituir um escolho, na hora de pensar algo de novo. O autor mostra-nos como historicamente o problema se desloca e causa perturbação no entendimento dos fenómenos mediáticos, que supõem sempre uma certa literacia, precisamente aquela que está implicada no uso de qualquer técnica. Sem dúvida, a construção dos fenómenos mediáticos deve ser problematizada, como apontam, por exemplo, Fernando Pereira Marques, no seu texto, e Moisés de Lemos Martins (2015), em "Os média na contemporaneidade. Da promessa de emancipação histórica à sua ruína".

Colocando-se numa perspetiva contra-hegemónica e crítica, o trabalho de Danielle Miranda analisa as manifestações identitárias nas narrativas dos estudantes, que se encontram nas fan pages de Facebook, do movimento "Ocupa Escola", no Brasil. A autora adota o conceito de multidão (Negri, 2004), para investigar o modo como nos seus perfis do Facebook os indivíduos envolvidos no movimento "Ocupa Escola" manifestam expressões identitárias. São destacados os temas da horizontalidade, da autonomia, da 
constituição de um movimento sem liderança; e também, da abertura à diversidade e da necessidade de reafirmar o cuidado público com a escola. A proposta da autora é a de que sejam repensados os velhos estatutos da identidade dos movimentos sociais. Em seu entender, esta questão deve partir do encontro de singularidades e explorar o modo como se produzem acontecimentos e se organiza uma linguagem comum, na consequência da indignação e do protesto.

A fechar a seção de artigos temáticos, Alexandre Ferreira e Jean-Martin Rabot refletem sobre as ambiguidades que atravessam os atuais discursos sobre a música eletrónica de dança, em particular o house e o techno. É seu propósito tornar visível o carácter socialmente construído de tais discursos. A tecnologia tem um papel central na transformação dos modos de produção e de compreensão da música no século XXI. Mais uma vez, o cerne da questão passa pelo atual regime discursivo, que ao conjugar o arcaísmo e o desenvolvimento tecnológico (Maffesoli, 2000, p. 35), misturando, por exemplo, músicas "populares" com músicas "eruditas", torna possível novas perceções sobre a música, embora no currículo prevaleçam as formas musicais "eruditas" ocidentais. AcoIhendo o ponto de vista dos Estudos Culturais, os autores insistem no facto de a música eletrónica de dança poder ser considerada como uma marca de resistência contra a elitização da música e contra os poderes e discursos instituídos.

Na seção Varia, Maria do Carmo Nino relata-nos uma vasta experiência ligada às artes plásticas, em diferentes setores, onde tem desempenhado vários papéis - produtora, curadora, analista, professora -, dando especial destaque a dois dos trabalhos que realizou como curadora: o Projeto MAMÃE e a exposição ContidoNãoContido, ocorrida no Museu Aloísio Magalhães (MAMAM), aberta ao público de março e setembro de 2010.

A encerrar este número da Revista Lusófona de Estudos Culturais / Lusophone Journal of Cultural Studies, Carla Cerqueira faz a recensão do livro que Manuel Carlos Silva, Maria Luísa Lima, José Manuel Sobral, Helena Araújo e Fernando Bessa Ribeiro, organizaram sobre Desigualdades e políticas de género. Para a autora, o que está em causa neste livro são as muitas desigualdades de género, que permanecem enraizadas na sociedade e que se manifestam, publicamente, tanto de forma explícita, como de forma implícita. E no que concerne às políticas públicas que as possam combater existe ainda um longo caminho a percorrer.

\section{REFERÊNCIAS BIBLIOGRÁFICAS}

Durin, S. (1992/2007). The Cultural Studies Reader. Londres, Nova Iorque: Routledge.

Foucault, M. (1975/2010). Microfísica do poder. Rio de Janeiro: Graal.

Laclau, E. \& Mouffe, C. (1985/2001). Hegemony and socialist strategy: Towards a radical democratic politics. London: Verso.

Maffesoli, M. (2000). L'instant éternel. Le retour du tragique dans les sociétés postmodernes. Paris: Denoël. 
Martins, M. L. (2015). Os média na contemporaneidade. Da promessa de emancipação histórica à sua ruína. In M. Ledo \& I. Lopes (Eds.), Comunicación, Cultura e Esferas de Poder (pp. 19-44). São Paulo: USP/USC/ Ass Ibercom/Agacom. Retirado de http://hdl.handle.net/1822/35292

Martins, M. L. (2017). A Linguagem, a Verdade e o Poder. Ensaio de Semiótica Social. Braga: CECS / Húmus.

Negri, A. (2004). Para uma definição ontológica da Multidão. Lugar Comum, 19-20, 15-26.

Weber, M. (2004). Economia e Sociedade - Vol. II. S. Paulo: Editora Universidade de Brasília.

\section{NOTAS BIOGRÁFICAS}

Moisés de Lemos Martins é Professor de sociologia da cultura e da comunicação na Universidade do Minho (Braga, Portugal), sendo nesta universidade Diretor do Centro de Estudos de Comunicação e Sociedade (CECS), que fundou em 2001. É autor de uma vasta obra académica no campo da epistemologia e sociologia da comunicação.

E-mail: moisesm@ics.uminho.pt; moiseslmartins@gmail.com

Morada: Centro de Estudos de Comunicação e Sociedade, Campus de Gualtar, Universidade do Minho, Braga 4710-057, Portugal

Urbano Sidoncha é licenciado em Filosofia pela Faculdade de Letras da Universidade de Lisboa e doutorado em Filosofia Contemporânea pela mesma Universidade. Professor auxiliar da Faculdade de Artes e Letras da Universidade da Beira Interior (UBI), foi o primeiro Diretor do Curso de Ciências da Cultura da UBI, cargo que exerceu entre 2013 e 2015, e Diretor do Curso de Filosofia de 2009 até 2016. Coordena atualmente o Mestrado em Estudos de Cultura da UBI, tendo sido também o seu primeiro Diretor. Investigador integrado do LabCom.IFP, é autor de diversos trabalhos científicos publicados em revistas nacionais e estrangeiras. Coeditou os livros Culturas em Movimento (Coleção ARS, Ed. LabCom.IFP, Covilhã, 2016) e Metamorfoses da Cultura (Ed. Vega, Lisboa, 2017).

E-mail: umestre@ubi.pt/usidoncha@gmail.com

Endereço: Universidade da Beira Interior, Rua Marquês D’Ávila e Bolama, 6201-001 Covilhã, Portugal

Messias Bandeira é Diretor do Instituto de Humanidades, Artes e Ciências Prof. Milton Santos, da Universidade Federal da Bahia - Brasil, e Professor do Programa de Pós-Graduação em Cultura e Sociedade. É Doutor em Comunicação e Cultura Contemporâneas e foi pesquisador visitante da New York University (Department of Media, Culture, and Communication). Coordena a Digitalia - Rede de Estudos Interdisciplinares sobre a Internet e a Cultura Digital.

E-mail:messias@ufba.br

Endereço: Instituto de Humanidades, Artes e Ciências Prof. Milton Santos - IHAC / UFBA, Rua Barão de Jeremoabo, S/No., PAF 5 - Campus de Ondina, Salvador-BA Brasil, CEP: 40.170-115 